\title{
Spatial distribution and survival of human and goat mesenchymal stromal cells on hydroxyapatite and beta-tricalcium phosphate
}

Citation for published version (APA):

Prins, H-J., Fernandes, H., Rozemuller, H., van Blitterswijk, C., de Boer, J., \& Martens, A. C. M. (2016). Spatial distribution and survival of human and goat mesenchymal stromal cells on hydroxyapatite and beta-tricalcium phosphate. Journal of Tissue Engineering and Regenerative Medicine, 10(3), 233-244. https://doi.org/10.1002/term.1681

Document status and date:

Published: 01/03/2016

DOI:

10.1002/term. 1681

Document Version:

Publisher's PDF, also known as Version of record

\section{Document license:}

Taverne

Please check the document version of this publication:

- A submitted manuscript is the version of the article upon submission and before peer-review. There can be important differences between the submitted version and the official published version of record.

People interested in the research are advised to contact the author for the final version of the publication, or visit the DOI to the publisher's website.

- The final author version and the galley proof are versions of the publication after peer review.

- The final published version features the final layout of the paper including the volume, issue and page numbers.

Link to publication

\footnotetext{
General rights rights.

- You may freely distribute the URL identifying the publication in the public portal. please follow below link for the End User Agreement:

www.umlib.nl/taverne-license

Take down policy

If you believe that this document breaches copyright please contact us at:

repository@maastrichtuniversity.nl

providing details and we will investigate your claim.
}

Copyright and moral rights for the publications made accessible in the public portal are retained by the authors and/or other copyright owners and it is a condition of accessing publications that users recognise and abide by the legal requirements associated with these

- Users may download and print one copy of any publication from the public portal for the purpose of private study or research.

- You may not further distribute the material or use it for any profit-making activity or commercial gain

If the publication is distributed under the terms of Article $25 \mathrm{fa}$ of the Dutch Copyright Act, indicated by the "Taverne" license above, 


\title{
Spatial distribution and survival of human and goat mesenchymal stromal cells on hydroxyapatite and $\beta$-tricalcium phosphate
}

\author{
Henk-Jan Prins $^{1 \dagger}$, Hugo Fernandes ${ }^{2 \dagger}$, Henk Rozemuller ${ }^{3}$, Clemens van Blitterswijk ${ }^{2}$, Jan de Boer ${ }^{2}$ \\ and Anton C. M. Martens ${ }^{1,4 *}$ \\ ${ }^{1}$ Department of Immunology, University Medical Centre Utrecht, The Netherlands \\ ${ }^{2}$ Department of Tissue Regeneration, University of Twente, Enschede, The Netherlands \\ ${ }^{3}$ Department of Clinical Pharmacy, Cell Therapy Facility, University Medical Centre Utrecht, The Netherlands \\ ${ }^{4}$ Department of Cell Biology, University Medical Centre Utrecht, The Netherlands
}

\begin{abstract}
The combination of scaffolds and mesenchymal stromal cells (MSCs) is a promising approach in bone tissue engineering (BTE). Knowledge on the survival, outgrowth and bone-forming capacity of MSCs in vivo is limited. Bioluminescence imaging (BLI), histomorphometry and immunohistochemistry were combined to study the fate of gene-marked goat and human MSCs (gMSCs, hMSCs) on scaffolds with different osteoinductive properties. Luciferase-GFP-labelled MSCs were seeded on hydroxyapatite (HA) or $\beta$-tricalcium phosphate (TCP), cultured for 7 days in vitro in osteogenic medium, implanted subcutaneously in immunodeficient mice and monitored with BLI for 6 weeks. The constructs were retrieved and processed for histomorphometry and detection of luciferase-positive cells (LPCs). For gMSCs, BLI revealed doubling of signal after 1 week, declining to $60 \%$ of input after 3 weeks and remaining constant until week 6 . hMSCs showed a constant decrease of BLI signal to $25 \%$ of input, indicating no further expansion. Bone formation of gMSCs was two-fold higher on TCP than HA. hMSCs and gMSCs control samples produced equal amounts of bone on TCP. Upon transduction, there was a four-fold reduction in bone formation compared with untransduced hMSCs, and no bone was formed on HA. LPCs were detected at day 14 , but were much less frequent at day 42 . Striking differences were observed in spatial distribution. MSCs in TCP were found to be aligned and interconnected on the surface but were scattered in an unstructured fashion in HA. In conclusion, the spatial distribution of MSCs on the scaffold is critical for cell-scaffold-based BTE. Copyright (C) 2012 John Wiley \& Sons, Ltd.
\end{abstract}

Received 23 April 2012; Revised 18 July 2012; Accepted 14 November 2012

Keywords mesenchymal stromal cells; bioluminescence imaging; hydroxyapatite; $\boldsymbol{\beta}$-tricalcium phosphate; spatial distribution; bone tissue engineering

\section{Introduction}

Combining synthetic materials (scaffolds) with bone marrow-derived mesenchymal stromal cells (MSCs) is one of the strategies in bone tissue engineering (BTE) for the treatment of patients suffering from large bone defects (Quarto et al., 2001; Chatterjea et al., 2010) or for patients

*Correspondence to: A. C. M. Martens, Department of Immunology, University Medical Centre Utrecht, Lundlaan 6, 3584 EA, Utrecht, The Netherlands.E-mail: a.martens@umcutrecht.nl

${ }^{\top}$ These authors contributed equally to this study. who need bone augmentation for dental implants (Schimming and Schmelzeisen, 2004; Klijn et al., 2010). Although multipotent MSCs can be produced from different tissues (Pittenger et al., 1999; Jiang et al., 2002), the most frequently used sources until now are bone marrow (Pittenger et al., 1999; Friedenstein et al., 1976; Caplan, 1991; Prockop, 1997; Gronthos et al., 2003) and adipose tissue (Zuk et al., 2001), but the list of tissues from which MSCs can be produced is rapidly increasing (Baksh et al., 2004; Porada et al., 2006; Kolf et al., 2007). A variety of porous calcium phosphate ceramics are being developed as scaffolds for BTE constructs. Culture-expanded MSCs 
are seeded on these scaffolds, subsequently induced to differentiate in vitro into the osteogenic lineage, and implanted in vivo, after which MSCs further differentiate into osteoblasts and deposit bone tissue onto the ceramic surface. The osteoinductive and osteoconductive potential of the ceramics can be modulated by varying the material characteristics, such as chemical composition, surface topography and geometry, thereby affecting the resorption rate and cell-material interactions (WilsonHench, 1987; Albrektsson and Johansson, 2001; Yuan et al., 2010). The exact underlying mechanisms that lead to bone induction by these synthetic materials thus far remain largely unknown. For goat MSCs it was shown that, when combined with scaffold materials, the MSCs contributed to a $>10$-fold increase in bone deposition compared with scaffold material without MSCs, with little variation between different goat MSC donors (Kruyt et al., 2007). Previous studies have demonstrated that bone deposition by human MSCs is far less reproducible than in the case of goat or rat MSCs (Chatterjea et al., 2010; Siddappa et al., 2007; Prins et al., 2009).

MSCs are highly amenable to genetic modification, thus enabling the introduction of reporter constructs to facilitate monitoring of cell proliferation during in vivo cell-based BTE using bioluminescent imaging (BLI). BLI is based on the detection of light emitted from luciferase gene-marked cells and allows non-invasive visualization of luciferase gene expression in living animals using a sensitive charge-coupled device (CCD) camera for detection of low quantities of photons (Wu et al., 2001; Honigman et al., 2001; Rabinovich et al., 2008). By repeated imaging of the same animal, localization and the level and duration of luciferase transgene expression can be monitored in real-time (Contag and Bachmann, 2002; Liu et al., 2010). Previous studies have illustrated that BLI is a powerful technique for non-invasive imaging of luciferase-marked cells in oncological diseases (Paroo et al., 2004; Rozemuller et al., 2008; Würdinger et al., 2008; Postnov et al., 2009; Caretti et al., 2011) to study T cell dynamics (Hardy et al., 2001; Na et al., 2010) and for studies in BTE (Blum et al., 2003; de Boer et al., 2006; Degano et al., 2008; Geuze et al., 2010). However, most of these studies in BTE were performed with cell lines or with MSCs from non-human mammalian species, only with endpoint measurements and not tested in combination with different types of calcium phosphate ceramics. Luciferase-GFP gene marking enables the selection of labelled cells and visualization of the physical interaction of MSCs with the carrier material, since luciferase-labelled cells can be detected post mortem in tissues of choice, including explanted scaffolds, using immunohistochemistry (Geuze et al., 2010).

In this study we report the first use of lentiviral labelling of MSCs with luciferase-GFP marker genes in combination with BLI to monitor the spatial distribution of goat as well as human MSCs after seeding on two types of porous calcium phosphate ceramics, differing in osteogenic potential, to determine in vivo MSC survival and spatial distribution and their contribution to in vivo bone formation.

\section{Materials and methods}

\subsection{Cell culture}

Human bone marrow was collected from the iliac crest after we were given written informed consent and approval of the procedure by the medical ethical committee of the institute (University Medical Centre Utrecht, The Netherlands). Goat bone marrow was obtained from the iliac crest as previously described (Geuze et al., 2009). All experiments involving animals were performed after acquiring permission of the local ethical committee for animal experimentation, in compliance with the institutional guidelines on the use of laboratory animals and according to the current Dutch Animal Experimentation Act. Goat MSCs (gMSCs) and human MSCs (hMSCs) were produced by culture, expanding the plastic adhering cell fraction from the bone marrow in tissue culture flasks after Ficoll density gradient separation. Human cells were plated at a density of 250000 nucleated cells $/ \mathrm{cm}^{2}$ and cultured in hMSC proliferation medium, which consists of minimal essential medium ( $\alpha$-MEM, Life Technologies) supplemented with $100 \mathrm{U} / \mathrm{ml}$ penicillin (Life Technologies), $10 \mu \mathrm{g} / \mathrm{ml}$ streptomycin (Life Technologies) and 5\% human platelet lysate, as previously described (Prins et al., 2009). Goat bone marrow cells were plated at 500000 nucleated cells $/ \mathrm{cm}^{2}$ in $\alpha$-MEM (Life Technologies), 15\% heat-inactivated fetal bovine serum (FBS; Cambrex), 2 mML-glutamine (Life Technologies), $100 \mathrm{U} / \mathrm{ml}$ penicillin (Life Technologies) and $10 \mu \mathrm{g} / \mathrm{ml}$ streptomycin (Life Technologies) as previously described (Geuze et al., 2010). All cells were maintained in a humidified incubator at $37^{\circ} \mathrm{C}$ and $5 \%$ $\mathrm{CO}_{2}$. The medium was refreshed twice a week and cells were detached by trypsin treatment upon reaching near-confluence and used for further subculture or cryopreservation.

\subsection{Lentiviral vector and virus production}

The self-inactivating (SIN) lentiviral vector used in this study was pRRL-cPPT-CMV-Luc2-IRESGFP-PRE-SIN, which contains a codon-optimized luciferase 2 fragment (Luc2) and GFP gene driven by the cytomegalovirus (CMV) promoter, separated by an internal ribosomal entry site (IRES). Generation of the vector and production of viral particles was performed as previously described (Geuze et al., 2010).

\subsection{Transduction and sorting of MSCs}

MSCs were thawed and plated in $175 \mathrm{~cm}^{2}$ Falcon filter-cap culture flasks (Becton Dickinson, Franklin Lakes, NJ, USA) and transduced when the MSC cultures reached approximately 50\% confluence. Transductions were carried out in the presence of $8 \mu \mathrm{g} / \mathrm{ml}$ hexadimethrine bromide (polybrene; Sigma, Zwijndrencht, The Netherlands) and 1:10 diluted lentiviral supernatant (transduction medium). 
The viral titre of the HEK293T culture supernatant was 1 500000 transducing $\mathrm{U} / \mathrm{ml}$. The multiplicity of infection (MOI) used for the transduction of goat and human MSCs was 1.5 . After $24 \mathrm{~h}$, the transduction medium was replaced with fresh proliferation medium. Upon reaching 90\% confluence, cells were harvested and GFP-positive cells were purified by flow sorting, using a FACSAria (BD). After sorting, 200000 cells/construct were seeded directly onto the scaffold materials, or in tissue culture flasks.

To determine luciferase activity during serial subculture of the MSCs, cells were washed twice with phosphatebuffered saline (PBS) and lysed in passive lysis buffer for $15 \mathrm{~min}$, insoluble cell debris was spun down and the supernatant fraction was assayed for luciferase activity, using the Dual-Luciferase Reporter Assay System (Promega, Leiden, The Netherlands).

\subsection{Scaffold materials}

Hydroxyapatite (HA) ceramics were prepared from HA powder (Merck, Germany), using the dual-phase mixing method, and sintered at $1250^{\circ} \mathrm{C}$ for $8 \mathrm{~h}$, as previously described (Li et al., 2003). $\beta$-Tricalcium phosphate (TCP) ceramics were prepared from TCP powder (Plasma Biotal, UK) and fabricated using the $\mathrm{H}_{2} \mathrm{O}_{2}$ method, as previously described (Yuan et al., 2002). Scaffold characteristics are depicted in Figure 1. The synthesized $2-3 \mathrm{~mm}$ scaffolds were cleaned ultrasonically with acetone, $70 \%$ ethanol and demineralized water, dried at $80^{\circ} \mathrm{C}$ and sterilized by autoclaving.

A
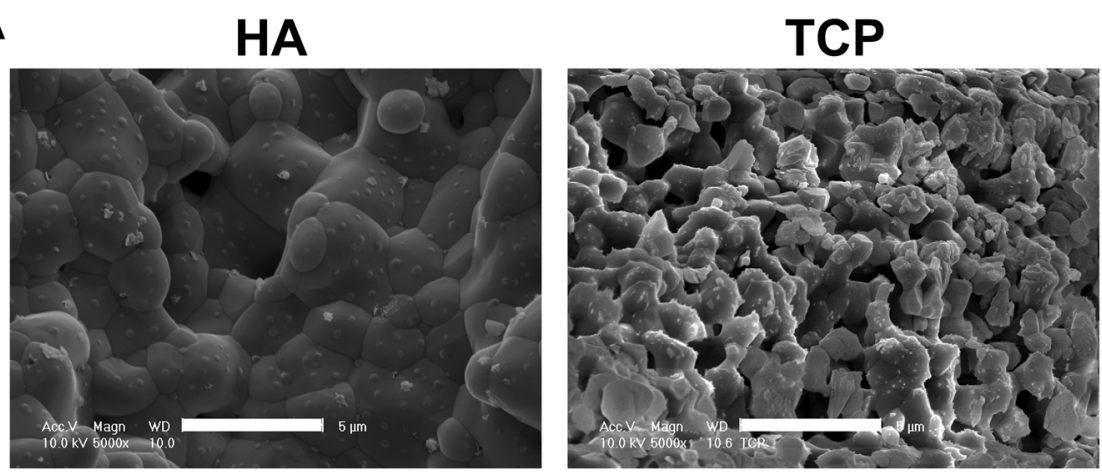

B

\begin{tabular}{ccc}
\hline & HA & TCP \\
\hline Chemistry & HA & $5 \%$ HA/95\% TCP \\
\hline Sintering temperature $\left({ }^{\circ} \mathrm{C}\right)$ & 1250 & 1100 \\
Sintering time $(\mathrm{h})$ & 8 & 8 \\
\hline Microporosity $(\%)^{*}$ & 3.1 & 48.7 \\
\hline Ca release $(\mathrm{ppm})$ & $0.9 \pm 0.1$ & $15.3 \pm 0.2$ \\
\hline
\end{tabular}

Figure 1. Characteristics of calcium phosphate ceramics. (A) SEM images depicting the microstructure of HA and TCP. (B) Chemistry, sintering temeprature $\left({ }^{\circ} \mathrm{C}\right)$, sintering time $(\mathrm{h})$, microporosity $(\%)$ and calcium release profile (ppm) of HA and TCP: ppm, parts per million; *volume percentage of micropores $>10 \mu \mathrm{m}$ within the calcium phosphate ceramic. Scale bars $=5 \mu \mathrm{m}$ 
Facility of the University of Utrecht. Sixteen RAG2 $2^{-/-} \mathrm{\gamma c}^{-/--}$ Balb/c male mice, 9 weeks old, were used. The animals were maintained in filter-top cages and supplied with autoclaved sterilized food pellets and $\mathrm{H}_{2} \mathrm{O}$ ad libitum. The surgical procedure was performed under general anaesthesia, using an intramuscular injection of $0.05 \mathrm{ml}$ from a mixture of anaesthetics (KXA; ketamine $100 \mathrm{mg} / \mathrm{ml}$, xylazine $20 \mathrm{mg} / \mathrm{ml}$ and atropine $0.5 \mathrm{mg} / \mathrm{ml}$, in a 7:6:1 ratio). After shaving, the surgical sites (on the backs of the mice) were cleaned with ethanol, subcutaneous pockets were made and hybrid constructs, consisting of three calcium phosphate ceramic scaffolds seeded with cells, were implanted in separate pockets. For each experimental group, eight separate constructs were implanted in eight individual mice (Table 1). Separate mice were used for goat and human samples. The incisions were closed using a vicryl 5-0 suture. After surgery the animals were treated with a subcutaneous injection of buprenorphine (Temgesic $0.05 \mathrm{mg} / \mathrm{kg}$ body weight; Schering-Plough, Utrecht, The Netherlands) to relieve pain.

For evaluation of in vivo bone formation, anaesthetized mice $(n=6)$ were sacrificed after 6 weeks, using cervical dislocation, and the samples were retrieved from the mice, fixed in 4\% paraformaldehyde, dehydrated in an ethanol series, embedded in MMA and sectioned for histomorphometry. The sections were stained with $0.3 \%$ basic fuchsin (Klinipath, Duiven, The Netherlands) and 1\% methylene blue solution (Merck, Darmstadt, Germany) for routine histology and histomorphometry to analyse bone formation. Approximately $10 \mu \mathrm{m}$-thick sections were processed on a histological diamond saw (Leica SP1600). At least three non-consecutive sections per experimental condition were imaged and the percentage of bone per scaffold area was calculated using KS400 software v 3 (Zeiss, Hamburg, Germany), as previously described (Teixeira et al., 2010).

\subsection{In vivo bioluminescent imaging}

For real-time monitoring of the luciferase-labelled cells, the mice received an intramuscular injection of $0.05 \mathrm{ml} \mathrm{KXA}$. Subsequently, the mice were injected intraperitoneally with $2.5 \mathrm{mg}$ D-luciferin (Synchem OHG, Kassel, Germany) in $100 \mu \mathrm{l}$ PBS, $5 \mathrm{~min}$ prior to monitoring light emission. In vivo optical imaging for luciferase was performed by collecting the photons emitted from luciferase-expressing cells and integrated for a period of $10 \mathrm{~min}$, using the $\Phi$-Imager (Biospace Lab, Paris, France) to generate a bioluminescence image, which was overlaid with a visible light image to determine the positions of the scaffolds. M3Vision Software was used to quantify the amount of emitted photons per second and per area (average surface radiance $=$ photons/ $\mathrm{s} / \mathrm{cm}^{2} / \mathrm{sr}$ ), by drawing a region of interest (ROI) across the scaffold, with background subtraction of the read-out from an area of equal size. The mice were imaged for the first time on day 2 and subsequently weekly for 6 weeks.

\subsection{Histological processing and identification of implanted MSCs}

On days 14 and 42, one mouse from each experimental group was sacrificed for immunohistochemistry (Table 1). After retrieval of the scaffolds and fixation in $4 \%$ paraformaldehyde for $24 \mathrm{~h}$ at room temperature, the HA scaffolds were decalcified in $4 \%$ formic acid for $6 \mathrm{~h}$, and the TCP scaffolds for 3 days in $12.5 \% \mathrm{w} / \mathrm{v}$ EDTA in distilled water. The decalcified scaffolds were dehydrated in an ethanol series, embedded in paraffin wax and $5 \mu \mathrm{m}$ sections were prepared. Sections were stained with routine histology haematoxylin and eosin (H\&E) staining and stained for luciferase-positive cells as previously described (Geuze et al., 2010). Briefly, luciferase-transduced cells were identified using a rabbit anti-luciferase antibody (CR 2029 RAP, Cortex Biochem, San Leandro, CA, USA), 1:100 (0.5 $\mu \mathrm{g} / \mathrm{ml} \mathrm{IgG})$ in PBS $/ 5 \%$ bovine serum albumin (BSA; Roche, Woerden, The Netherlands). As an isotype control, rabbit IgG $(0.5 \mu \mathrm{g} / \mathrm{ml}$, X0903; Dako, Glostrup, Denmark) was used. Sections were pretreated with $1.5 \% \mathrm{H}_{2} \mathrm{O}_{2}$ and incubated with the antibodies overnight at $4{ }^{\circ} \mathrm{C}$. Finally, the samples were incubated with goat anti-rabbit horseradish peroxidase (P0448, Dako) at $2.0 \mu \mathrm{g} / \mathrm{ml}$ in PBS/5\%BSA for $60 \mathrm{~min}$ at room temperature, and detected using $3,3^{\prime}$-diaminobenzidine (DAB) staining. Counterstaining was performed with Mayer's haematoxylin.

\subsection{Statistical analysis}

For each experiment, data are presented as mean standard deviation (SD), unless otherwise indicated. Correlations between the calculated cumulative cell number production and BLI signals during the experiment were assessed by Spearman's rank correlation coefficient, using GraphPad Prism 4 statistical analysis software. DNA read-out data and data on bone formation for the different groups were analysed by one-way analysis of variance (ANOVA) and Tukey's multiple comparison test correction, using Graphpad Prism 4 software. The outcome of a comparative test was considered statistically significant when $p<0.01$.

Table 1. Experimental groups

\begin{tabular}{|c|c|c|c|c|c|c|}
\hline Experimental group & Scaffold & $\begin{array}{l}\text { Number of } \\
\text { MSCs/implant }\end{array}$ & Luciferase transduced & $\begin{array}{c}\text { BLI (days } 2,7,14,21,28,35,42) \\
\% \text { in vivo bone (day } 42 \text { ) }\end{array}$ & $\begin{array}{l}\text { HE and } \alpha \text {-Luc } \\
\quad \text { (day } 14)\end{array}$ & $\begin{array}{l}\text { HE and } \alpha \text {-Luc } \\
\text { (day } 42 \text { ) }\end{array}$ \\
\hline TCP & TCP & 200000 & No & $n=6$ & $n=1$ & $n=1$ \\
\hline TCP-Luc & $\mathrm{TCP}$ & 200000 & Yes & $n=6$ & $n=1$ & $n=1$ \\
\hline HA-Luc & $\mathrm{HA}$ & 200000 & Yes & $n=6$ & $n=1$ & $n=1$ \\
\hline
\end{tabular}




\section{Results}

\subsection{Preparation and characterization of luciferase-marked MSCs}

Transduction of goat and human MSCs with a MOI of 1.5 resulted in a transduction efficiency of approximately 50\% for both cell types, on the basis of GFP expression measured by flow cytometry. The subpopulation of GFP-positive cells was purified using a FACSAria cell sorter. Analysis of the sorted fraction for GFP indicated $>95 \%$ purity (data not shown). During an in vitro culture period of 7 weeks, we analysed cell proliferation and the level of GFP, as well as luciferase expression at each passage. For goat as well as for human, $>90 \%$ of the gene-marked MSCs expressed GFP throughout the 7 weeks of in vitro culture and the luminescence signal per cell remained constant. Using these parameters, we calculated the cumulative cell numbers and the cumulative luciferase activity. A correlation between growth and the BLI signal was observed for MSCs from both species $(p<0.001)$, indicating that the BLI signal correlates with the number of cells and that the luciferase activity/cell is not decreased during prolonged cell cycling (Figure 2). We observed only a minimal difference in the

A
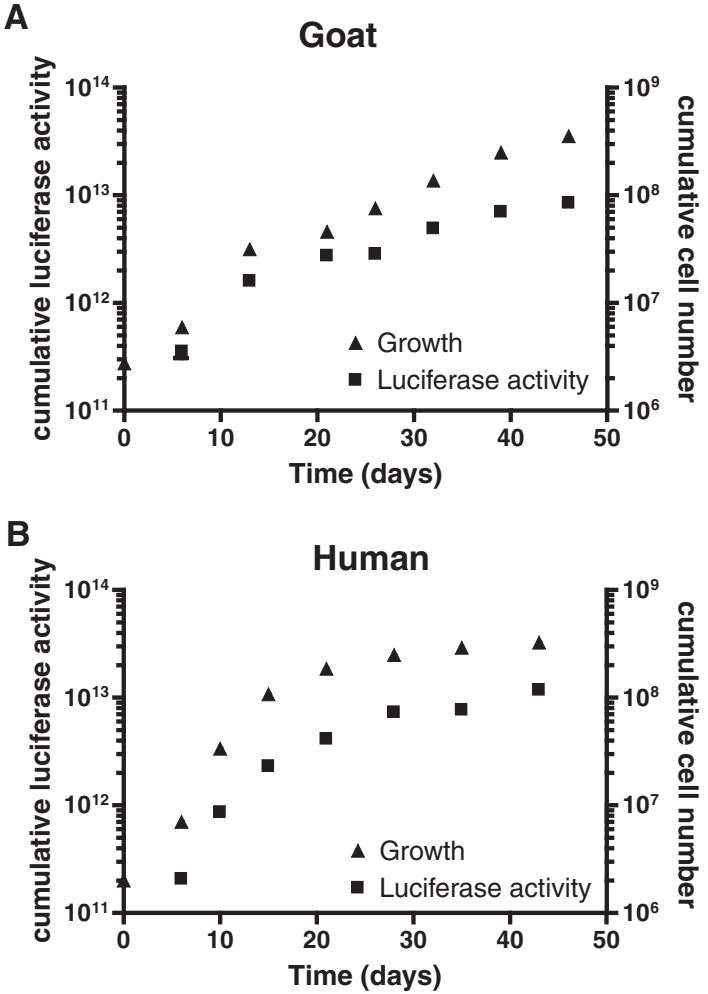

Figure 2. Stability of luciferase expression during prolonged in vitro culture. Luciferase-GFP-positive cells, purified by flow sorting, were cultured for 7 weeks in vitro. During serial subculture of the MSCs, the cells were counted and the luciferase signal was determined in triplicate. Data are presented as mean \pm SD. Cumulative cell numbers (right $y$ axis) and the cumulative luciferase signal (left $y$ axis) were calculated and plotted against time. Correlation was observed between the growth and the luciferase signal of luciferase-positive goat MSCs (A) as well as human MSCs (B) over time $(p<0.001)$ mean BLI signal/cell between goat and human MSCs (42 $300 \pm 14600$ vs $27300 \pm 5$ 021, respectively).

\subsection{Expansion and distribution of seeded MSCs on scaffolds}

To determine the in vitro expansion of the cells after seeding 200000 MSCs on HA and TCP, the amount of DNA was measured after 1 and 7 days of in vitro culture. For gMSCs, no significant differences were found in the amount of DNA extracted from TCP and HA for non-transduced or transduced cells after 1 and after 7 days of culture, respectively (Figure 3A). This indicates that the cell number 1 day after seeding and the subsequent cell expansion were comparable for gMSCs seeded on TCP and HA prior to implantation. Also, for hMSCs no significant differences were observed on day 1 , indicating that the cell numbers were similar for all groups. However, at day 7, significantly lower amounts of DNA were found in the HA-Luc group compared to TCP loaded with untransduced or transduced MSCs (Figure 3B). This indicates that hMSCs expansion on HA is substantially lower than on TCP, which results in differences in cell content on the scaffolds on the day of implantation (at day 7).
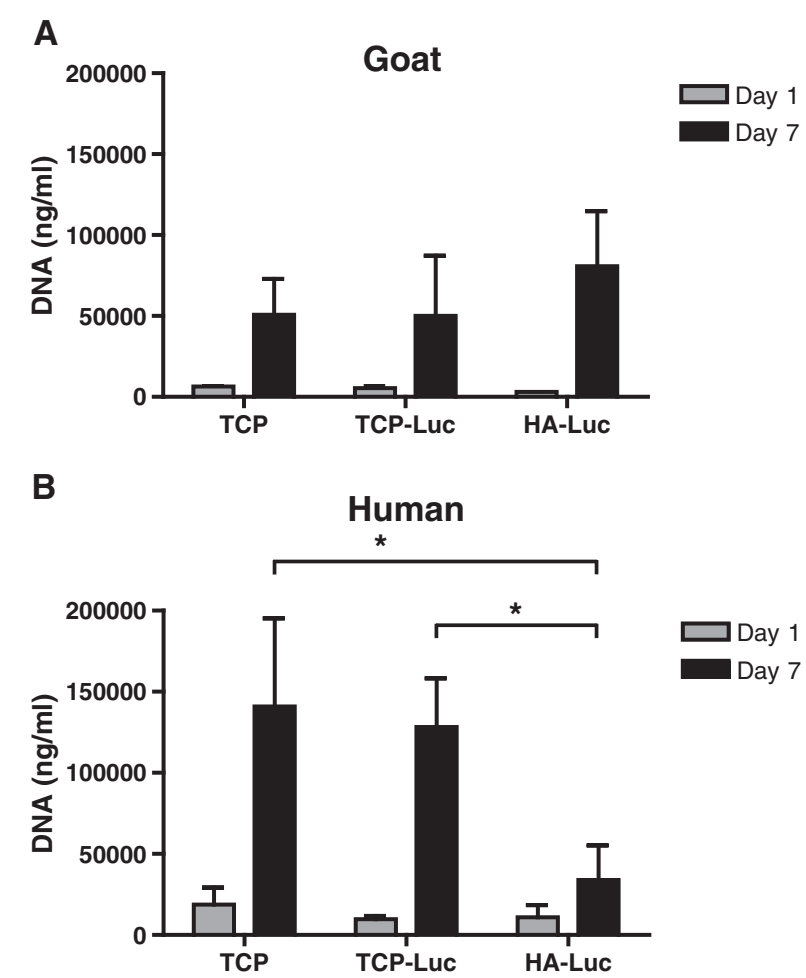

Figure 3. DNA assay. As a measure of cell content, the amount of DNA ( $\mathrm{ng} / \mathrm{ml}$ ) extracted from MSC-seeded scaffolds was determined at day 1 (grey bars) and day 7 (black bars) after seeding 200000 non-transduced and luciferase-positive goat (A) and human (B) MSCs onto HA and TCP. Data are presented as mean SD. Differences between the amount of DNA/scaffold for the different groups were analysed by one-way ANOVA and Tukey's multiple comparison test and considered to be significant when $p<0.01$; these are marked * 
Therefore, we studied the spatial distribution of the seeded cells in the scaffolds prior to implantation. MSCs of each group and both species were loaded on HA and TCP, cultured for 14 days in vitro, embedded in MMA and analysed. The spatial organization of the MSCs on TCP was strikingly different from that on HA, irrespective of the species. In contrast to the orderly structured layer of interconnected cells lining the surface of the pores in TCP, the MSCs were more randomly distributed throughout the pore available space in HA (Figure 4).

\subsection{In vivo bone formation}

A most relevant parameter in this study was the amount of newly formed bone six weeks after implantation. Representative images of a stained section for each of the groups are shown in Figure 5. Bone formation was similar for transduced and non-transduced gMSCs on TCP $(12.7 \pm 4.4 \%$ vs $13.3 \pm 4.6 \%)$ (Figure $6 \mathrm{~A})$. This indicates that the viral transduction did not affect the in vivo bone-forming capacity of the goat MSCs. In contrast, bone formation by transduced hMSCs was significantly lower compared to non-transduced hMSCs $(2.9 \pm 1.8 \%$ vs $13.0 \pm 6.2 \%$ ) (Figure 6B). Apparently, the lentiviral transduction procedure followed by flow sorting has an effect on the bone-forming capacity of the hMSCs, but nevertheless substantial amounts of bone were produced. Bone formation by transduced gMSCs was significantly lower on HA than on TCP $(5.7 \pm 2.4 \%$ vs $12.7 \pm 4.4 \%)$; transduced hMSCs formed low amounts of bone on TCP, but bone formation was totally absent on HA $(2.9 \pm 1.8 \%$ vs 0\%) (Figure 6A, B). This indicates, for both species, that luciferase-marked MSCs retain their in vivo bone-forming capacity, and that the osteoinductive properties of TCP are superior to those of HA.

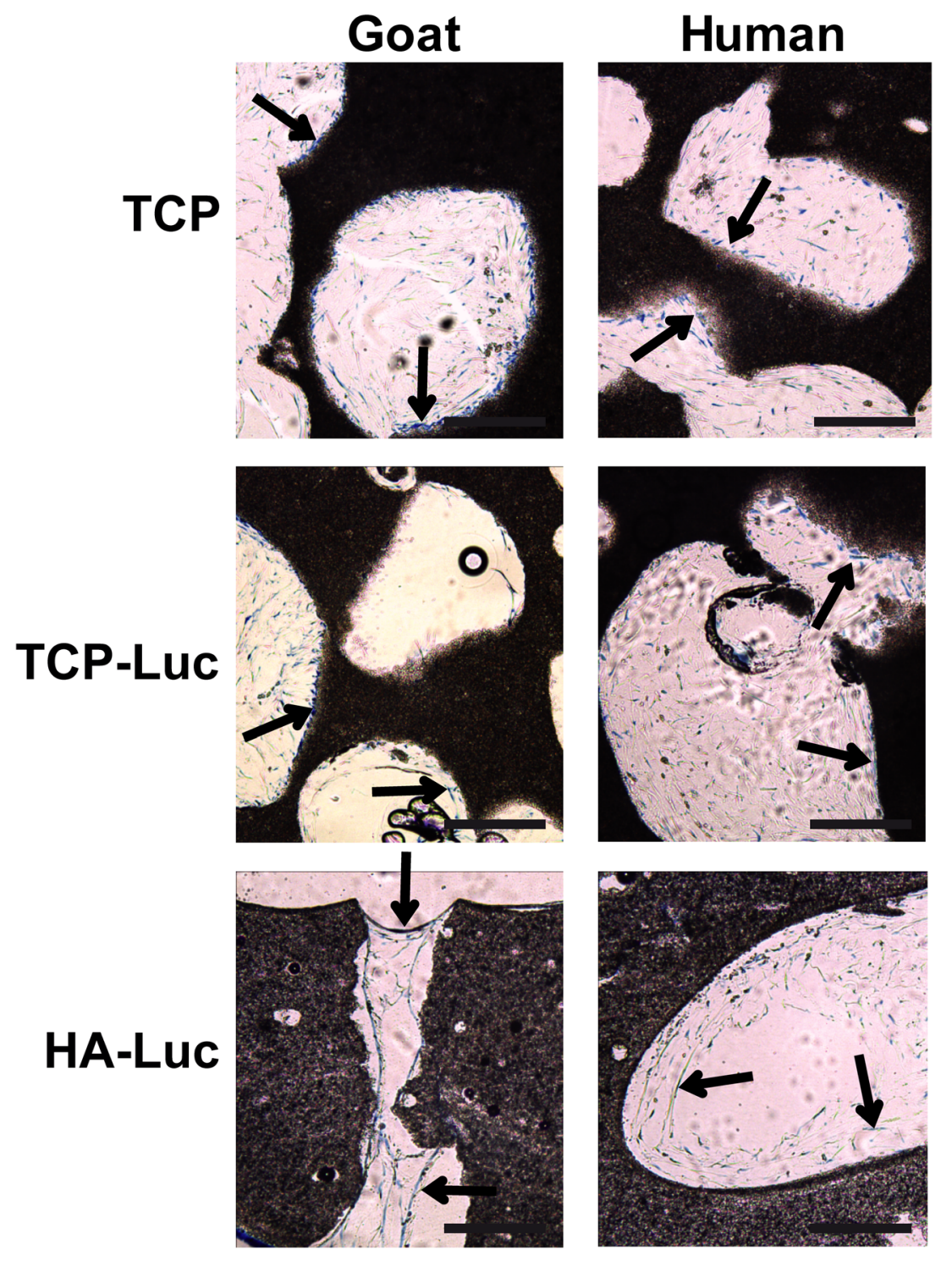

Figure 4. In vitro localization and distribution of the cells on scaffolds. Localization and distribution of the seeded cells prior to implantation were evaluated by culturing non-transduced (upper row) and luciferase-marked (middle and lower rows) goat MSCs (left column) and human MSCs (right column) for 14 days in vitro on TCP and HA, embedded in methyl methacrylate and stained with $1 \%$ methylene blue. Arrows, locations of sheets of connected cells; on TCP these are attached to the surface of the scaffold material (black), and on HA primarily in the pores of the scaffold. Scale bars $=100 \mu \mathrm{m}$ 


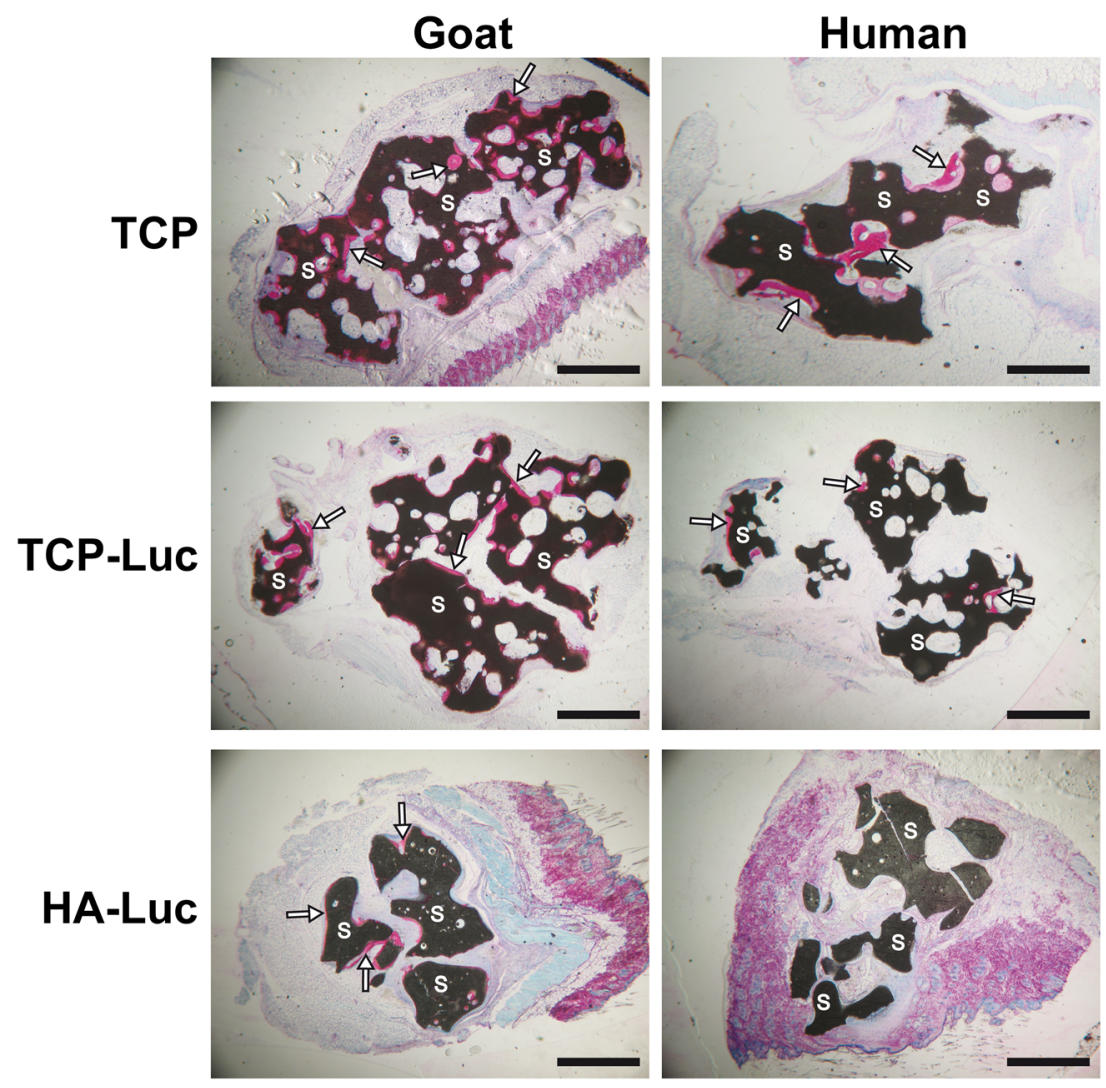

Figure 5. In vivo bone formation, which was tested in an ectopic model in immune-deficient mice. Images of representative histological sections of methylmethacrylate-embedded sections stained with $1 \%$ methylene blue and $0.3 \%$ basic fuchsin are depicted. Scaffold material is shown in grey/black (S), newly formed bone is basic fuchsin-stained pink (white arrows). Bone formation by non-transduced MSCs on TCP and luciferase-transduced MSCs on TCP and HA are shown from top to bottom, respectively (left column, goat MSCs; right column, human MSCs). Samples shown are from 42 days. Scale bars $=1 \mathrm{~mm}$

\subsection{In vivo bioluminescent imaging of the luciferase-marked MSCs}

The in vivo BLI monitoring of transduced gMSCs showed an increase of the luciferase signal from the start (day 2) until day 7 for both HA-Luc and TCP-Luc, indicating cell proliferation in vivo after implantation (Figure 7A). On day 7 the increase was nearly a factor of 2 for both groups, i.e. from $35712 \pm 7476$ to $86912 \pm 25491$ photons $/ \mathrm{s} / \mathrm{cm}^{2} / \mathrm{sr}$ for the HA-Luc group and from $94739 \pm 25809$ to 168 $380 \pm 21652$ photons $/ \mathrm{s} / \mathrm{cm}^{2} / \mathrm{sr}$ for the TCP-Luc group, which implies that early after implantation gMSCs proliferate equally well on TCP and HA (Figure 7A).The higher BLI readout values for the TCP group are also reflected in the superior bone formation on day 42 (Figure 6A). For hMSCs we observed a constant decrease of the luciferase signal in time for both groups (Figure 7B), meaning that after in vivo implantation transduced hMSCs did not proliferate further. The same proportional decline was observed for both groups. Similar to what was observed for gMSCs, the luciferase signal was much lower on HA (three-fold) than on TCP (2 $218 \pm 489$ vs $6591 \pm 2873$ photons/s/ $\mathrm{cm}^{2} / \mathrm{sr}$ ) (Figure 7B). This indicates that hMSCs were more structured bound to TCP than to HA (Figures 3B, 4), thereby explaining the superior bone formation of hMSCs on TCP vs HA (Figure 6B). The much lower initial readout in BLI signal for the HA group is in agreement with the earlier observation of a lower degree of MSCs attachment to HA than to TCP.

\subsection{Identification of luciferase-marked MSCs after implantation}

To verify the involvement of the luciferase-labelled cells in the process of bone formation, paraffin sections from scaffolds that were retrieved at days 14 and 42 were stained with H\&E and adjacent sections were processed with immunohistochemistry to detect the presence of luciferasepositive cells (LPCs), using an anti-luciferase antibody. At day 14, LPCs were detected for both species in HA- as well as in TCP-based scaffolds (Figure 8A, B). For gMSCs bone formation was detected in all test groups, controls, HA and TCP. Luciferase-positive osteocytes as well as luciferasepositive osteoblasts were found at the luminal surfaces, implying that the onset of bone formation in the hybrid scaffolds started before day 14 , and also that the seeded cells were indisputably responsible for the observed bone formation. In HA samples bone formation was minimal and, typically, only at locations where LPCs were in contact with the scaffold material. For hMSCs the frequency of LPCs at day 42 was very low in both HA-Luc and TCP-Luc 

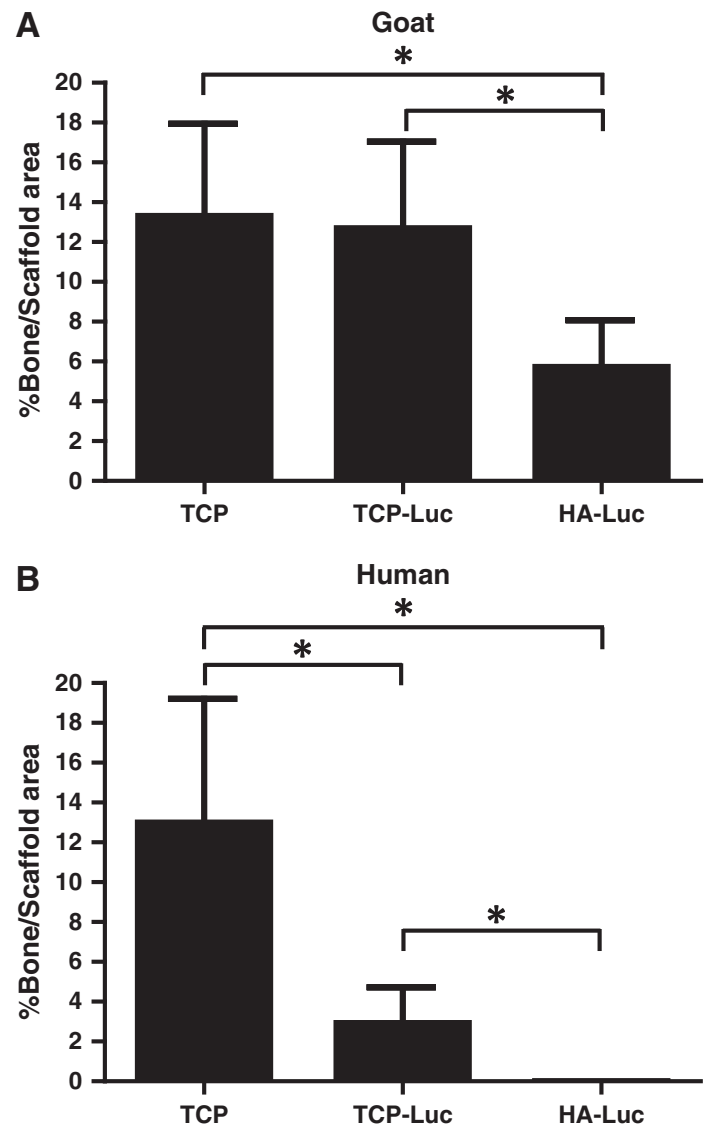

Figure 6. Quantification of in vivo bone formation. The average percentage of bone/scaffold area at day 42 is shown for nontransduced MSCs on TCP and luciferase-transduced MSCs on TCP and HA (bars from left to right) for goat MSCs (A) and human MSCs (B). Data are presented as mean \pm SD. Differences between bone formation for the different groups were analysed by one-way ANOVA and Tukey's multiple comparison test and were considered significant when $\boldsymbol{p}<0.01$; these are marked *

samples, but bone formation was only observed in TCP samples. These observations are in line with the analysis of the spatial distribution of the MSCs in the HA and TCP scaffolds, respectively, measured with methylene blue staining of the MMA-processed slides. In general, stromal cells were attached and lining the surfaces of the pores in TCP scaffolds but, in contrast, randomly distributed in the HA scaffolds (Figure 4). In control samples, in which non-transduced MSCs were seeded on the scaffolds, no LPCs were found in any of the sections after staining with the anti-luciferase antibody.

\section{Discussion}

In the present study we have used a combination of histology, histomorphometry, immunohistochemistry and in vitro and in vivo bioluminescence imaging to elucidate the spatial distribution, survival and expansion of cultured goat and human MSCs, after seeding on HA- or TCP-calcium phosphate ceramic scaffolds. We also determined the ensuing
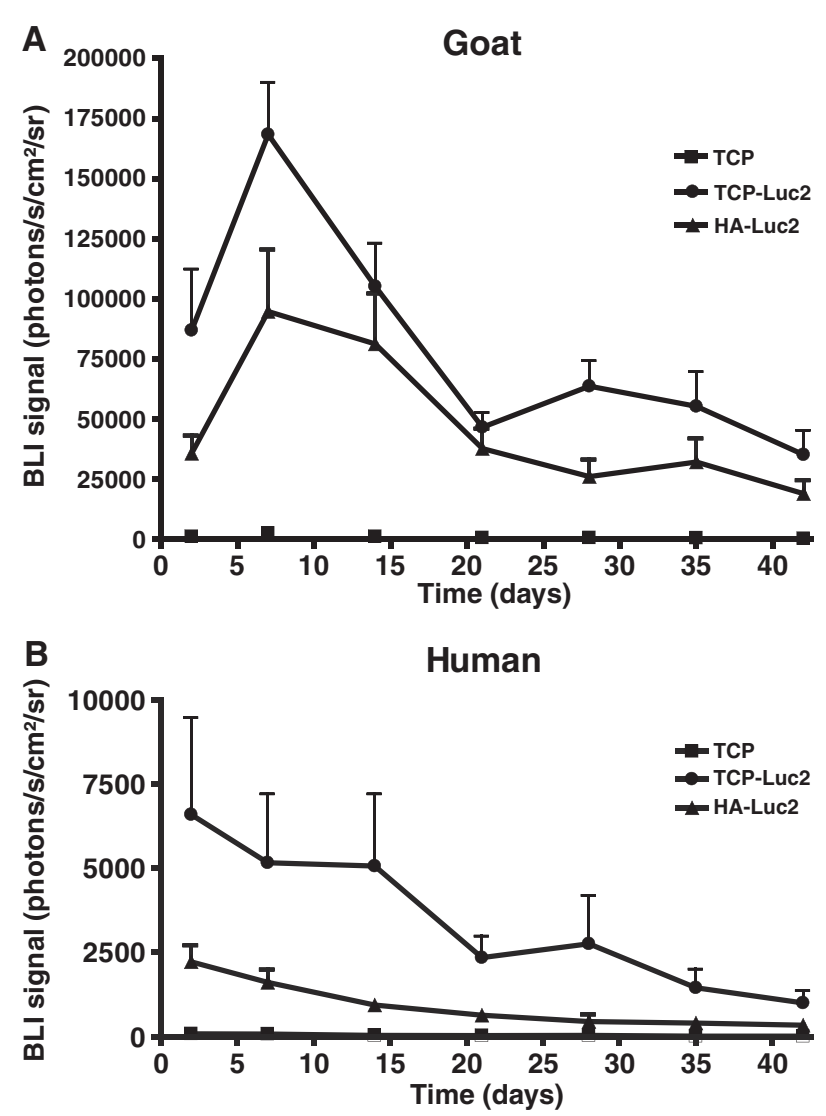

Figure 7. In vivo bioluminescence imaging of luciferase-positive cells. Bioluminescence imaging in vivo of luciferase-positive cells was performed by collecting the photons emitted from luciferase-expressing cells, using the Photon Imager and M3Vision Software. Emitted light was quantified by drawing a region of interest (ROI) and measuring light emission as photons $/ \mathrm{s} / \mathrm{cm}^{2} /$ sr with with background values subtracted. Mice were imaged for the first time at day 2 and subsequently weekly for 6 weeks. Data are shown as average \pm standard error of the mean

in vivo bone formation. Our data show that the spatial distribution of MSCs in the scaffold material correlate with the amount of bone that is being formed. The first indication came from the observation that the BLI signal from the luciferase-marked MSCs on day 2 was lower on HA for both species, suggesting a difference in outgrowth prior to implantation of the hybrid scaffolds. The observed initial lower BLI values on HA in comparison with TCP persisted until the end of the experiment. Whereas the gMSCs BLI curves showed a doubling of signal after 1 week, declining to $60 \%$ of input after 3 weeks and remaining constant until week 6 , hMSCs showed a constant decrease of BLI signal to $25 \%$ of input. These observations were irrespective of the ceramics used and showed that after implantation there was no extensive proliferation of the seeded hMSCs. Loss of luciferase expression was an unlikely explanation, because prolonged in vitro cell culture showed that luciferase expression was unaffected.

The in vivo bone formation of gMSCs on TCP was twofold higher than on HA and unaffected by gene marking; hMSCs and gMSCs on TCP produced equal amounts of bone, but hMSCs did not produce bone on HA. Transduced hMSCs on TCP, however, showed a four-fold reduced bone formation. Important factors that influence bone formation 
A
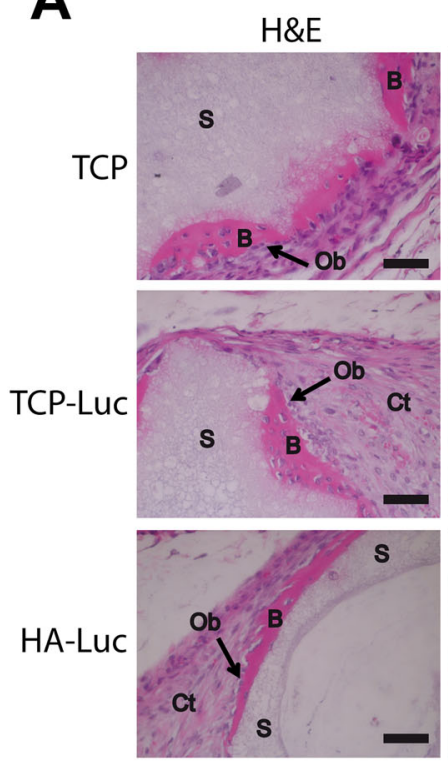

$\mathrm{T}=14$ Days
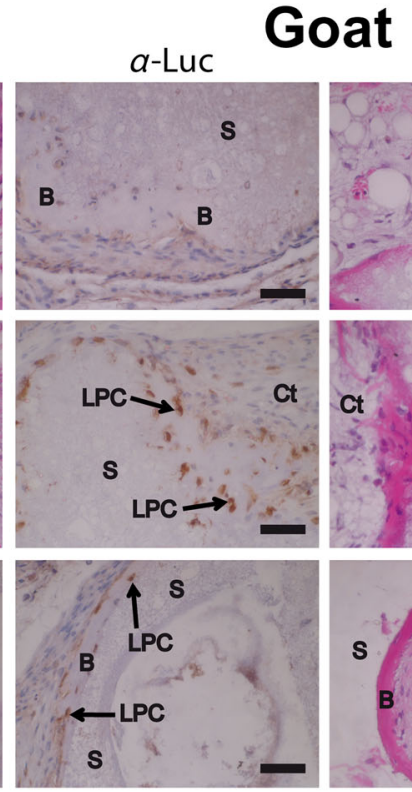

$s$
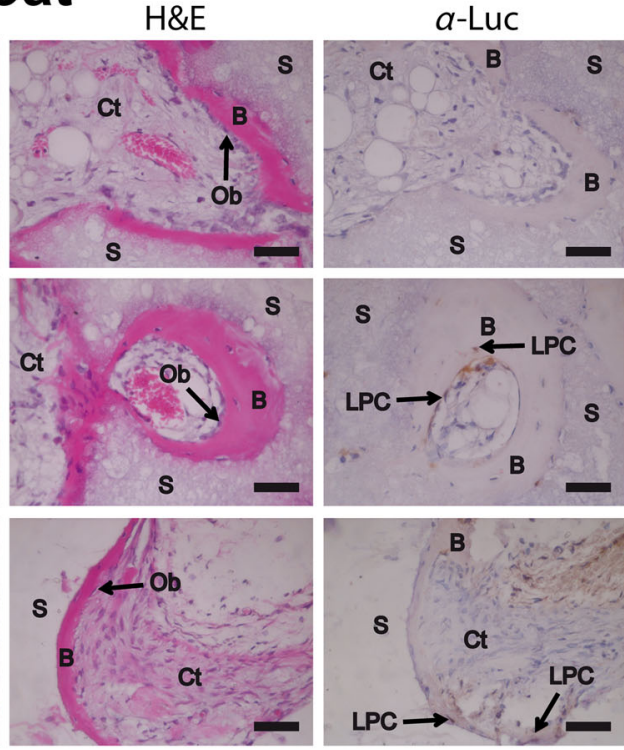

$\mathrm{T}=42$ Days

Human

B

$H \& E$
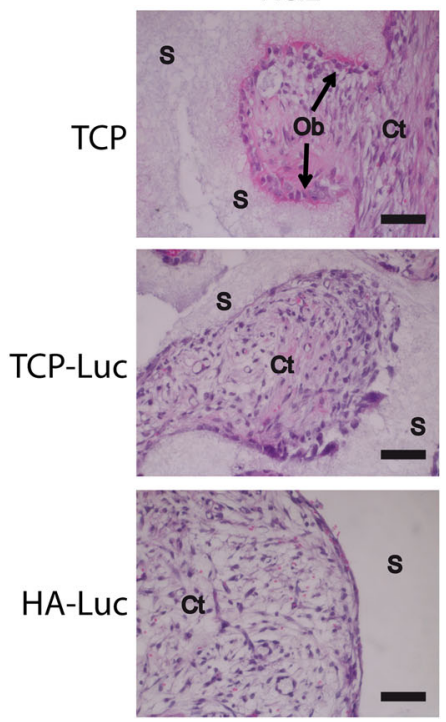

$\mathrm{T}=14$ Days
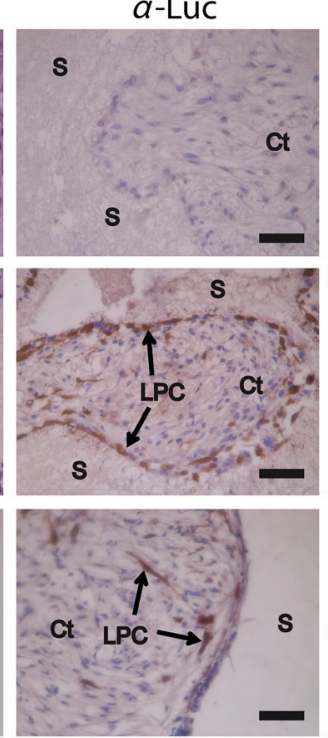

ays
$H \& E$
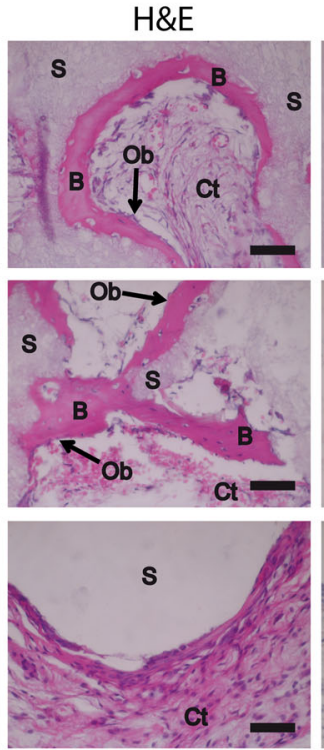

$\mathrm{T}=42$ Days

$a$-Luc
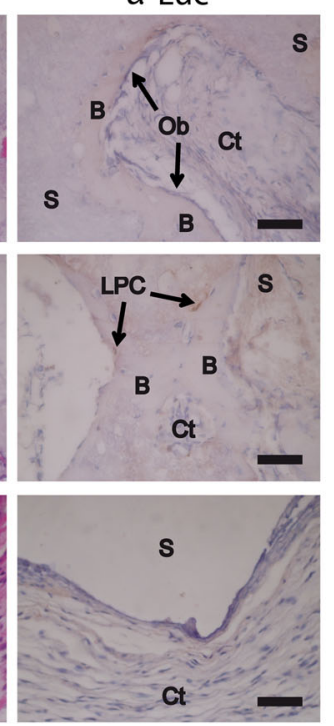

antatio

Figure 8. Immunohistochemical localization of luciferase-marked cells in scaffolds after implantation. Implanted scaffolds seeded with goat MSCs (A) or human MSCs (B) were retrieved from the mice on day 14 (columns 1, 2) and day 42 (columns 3, 4), embedded in paraffin and processed for routine histology (H\&E) staining (columns 1,3). To identify implanted goat MSCs (A) and human MSCs (B) ex vivo after implantation, adjacent sections were analysed with anti-luciferase antibodies ( $\alpha$-Luc) to detect luciferase-positive cells (LPCs; columns 2, 4). Scaffold material is grey (S); newly formed bone stains pink with eosin (B). The bone lining the scaffold contains embedded osteocytes and a osteoblastic layer $(\mathrm{Ob})$ is present on the luminal surfaces. Connective tissue (Ct) was present inside the lumen and between and around the scaffolds. Scale bars $=50 \mu \mathrm{m}$

are the number, quality and proliferation history of the cells. Previous reports on gMSCs showed that viable cells are required (Kruyt et al., 2003), that seeding of cells at higher densities and with higher proliferative capacity leads to an increase in BLI signal (Olivo et al., 2008; Geuze et al., 2010) and that preculture is an advantage for cell-based bone tissue engineering (Kruyt et al., 2006). In the present study, we used the same number of viable cells as were used by Kruyt et al. (2006) and precultured the cells before implantation (Kruyt et al., 2006). Despite the fact that the transduced hMSCs yielded a lower percentage of bone on TCP when compared to the non-transduced hMSCs, the presence of LPC in the newly formed bone demonstrates that MSCs seeded on the scaffolds contribute to in vivo bone formation. An additional factor that has only recently been recognized as a relevant issue may be found in the heterogeneity within MSC cultures (Dominici et al., 2009; Sarugaser et al., 2009; Russell et al., 2010; Phinney, 2012), leading to differences in multipotency as well as in in vivo bone-forming capacity (Kuznetsov et al., 1997; Siddappa et al., 2007; Prins 
et al., 2009). The lentiviral transduction and selection of GFP-positive MSCs could have resulted in the selection of a population of cells with less osteogenic potential. Osteoprogenitor cells were reported to be more slowly replicating, large cuboidal or flattened cells (Digirolamo et al., 1999; Colter et al., 2000, 2001; Sekiya et al., 2002; Smith et al., 2004), which could make them less susceptible to viral transduction than smaller, rapidly proliferating cells. Human MSCs exhibit morphological changes and loss of in vivo osteogenic potential during passage (Siddappa et al., 2007; Agata et al., 2010), whereas gMSCs consist of a more homogeneous population and showed fewer morphological changes and less loss of in vivo bone-forming potential during passage than hMSCs (unpublished results). Clonal analyses of hMSCs revealed differences between individual clones and their in vivo bone-forming capacity (Kuznetsov et al., 1997; Lee et al., 2010). These observations indicate that substantial differences may exist in cellular composition of culture-expanded MSC populations, which could explain different cellular behaviours between gMSCs and hMSCs.

Key components for successful cell-based bone tissue engineering are the presence of a carrier material as well as osteogenic cells, and this highly depends on multiple interaction parameters, of which one is the osteoinductivity of the calcium phosphate ceramic used. Different ceramic materials provide different cues to pre-osteogenic cells (Yuan et al., 2010). The calcium-enriched environment provided by porous TCP appeared to have a superior osteoinductive potential compared to HA. Therefore we selected these two extremes for this study. This study reveals that adherence and spatial distribution of adherent cells to the calcium phosphate ceramic are critical parameters in cell-scaffold BTE. Bone formation by gMSCs was unaffected by gene marking and cell numbers were equal before implantation. The amount of DNA recovered from the hybrid scaffold does not, however, give information on the binding of the MSCs to the scaffold surface and spatial distribution of the MSCs in the scaffold. Within the scaffold cells are exposed to different stimuli, depending on where they are: some cells can be found in close contact with the material surface, whereas others are in the pore and therefore not in direct contact with the material. Therefore, in addition to the heterogeneity of the cell population, the heterogeneity of the scaffold will decisively contribute to the observed phenotype.

To study whether physical interaction between the cells and the scaffolds can indeed occur, histological analysis gives a much better indication. We typically observed a more structured interconnected layer of cells lining the surfaces of the pores in TCP samples, whereas the cells were more randomly distributed throughout the pore available space in HA before implantation as well as 2 and 6 weeks post-implantation. That contact with the material is essential was further substantiated by the fact that in HA scaffolds only bone deposition was observed in those small areas where LPCs were in contact with the ceramic material.

We only studied ectopic implantation sites to rule out osteoconduction or periosteal bone formation by cells from the surrounding tissues, as these could act as disturbing mechanisms in our experimental conditions. The subcutaneously placed constructs also reduced attenuation of the light emission through the tissues of the animal when compared with deep tissue orthotopic locations (Paroo et al., 2004; Geuze et al., 2010).

For the experiments described here, we used lentivirallytransduced, luciferase-GFP-marked cells that were purified to almost homogeneity. Therefore, the presence of luciferasepositive cells within and on the new layer of bone is indicative that it was indeed the seeded MSCs that contributed to the initiation and they also participated in new bone formation by differentiating towards osteoblasts and osteocytes. Goat luciferase-positive cells within the newly formed bone were already observed in samples at day 14 , indicating that bone formation by the implanted cells started before week 2. In addition, day 14 is the first time point demonstrating a decrease in BLI signal. It is likely that at this time point the total scaffold surface is covered with a layer of stromal cells, leading to a slow-down or even a decrease in proliferation of the cells, and may indicate the onset of differentiation towards bone-forming stromal cells. Olivo et al. (2008) reported an increase of BLI signal during 7 weeks. However, in that study the hybrid scaffolds were implanted $20 \mathrm{~h}$ after seeding, leaving ample space for the luciferase-transduced cells to further expand in vivo. The moderate increase in BLI signal in vivo for the gMSCs in our study can be explained by the longer in vitro incubation of the gMSCs on the scaffolds pre-implantation (7 days vs $20 \mathrm{~h}$ ), resulting in a confluent layer of gMSCs covering the scaffold and, as such, obviating a long expansion period in vivo after implantation. In contrast to gMSCs, pre-incubation in vitro of the hMSCs prior to implantation to allow cell differentiation and extracellular matrix formation is, however, necessary for new bone formation in vivo by hMSCs (Siddappa et al., 2008; Song et al., 2009). Whether the development from proliferating osteoblastic cells towards in vivo osteocytes and the concurrent changes in metabolic activities and gene expression influences the expression of luciferase expression is still unclear. Metabolic differences between MSCs from distinct species can also account for the observed outcome. How efficiently MSCs use energy sources such as glucose and glutamine, and how they cope with the waste products, can affect they phenotype as well as survival (Schop et al., 2009). Although not analysed in this study, we feel that early events upon implantation of constructs in vivo can affect cell viability and subsequent proliferation potential. Therefore, cell-seeding efficiency and BLI measurements in the first hours and days can bring valuable information and should be performed in future experiments.

In summary, the present study with luciferase genemarked MSCs has provided new insights into the initial events in in vivo bone formation in hybrid scaffolds, in the kinetics of MSC survival and evidence that the seeded cells are involved in in vivo bone production on hybrid scaffolds. On TCP, bone formation by the seeded MSCs was superior to that on HA. To profit from the increased osteoinductive potential that is provided by the calcium-enriched environment of porous TCP, close contact of the osteogenic cells during in vitro pre-incubation, as well as in vivo, is essential. 
Our data show that the spatial distribution of MSCs on their scaffold is critical for the outcome of cellscaffold-based therapies.

\section{Acknowledgements}

The authors would like to thank Huipin Yuan from Xpand Biotechnology BV for kindly providing HA and TCP granules for the in vivo studies, Gerard Geelen and Kiki Hesp for excellent animal care, and Linda Aalders and Nathalie Groen for technical
assistance.This study was financially supported by a grant from the Dutch Programme for Tissue Engineering (Project No. UGT 6729) and is part of the University Medical Centre Utrecht programme for regenerative medicine.

\section{Conflict of interest}

The authors have declared that there is no conflict of interest.

\section{References}

Agata H, Asahina I, Watanabe N et al. 2010; Characteristic change and loss of in vivo osteogenic abilities of human bone marrow stromal cells during passage. Tissue Eng Part A 16: 663-673.

Albrektsson T, Johansson C. 2001; Osteoinduction, osteoconduction and osseointegration. Eur Spine J 10(suppl 2): S96-101.

Baksh D, Song L, Tuan RS. 2004; Adult mesenchymal stem cells: characterization, differentiation, and application in cell and gene therapy. J Cell Mol Med 8: 301-316.

Blum JS, Barry MA, Mikos AG et al. 2003; In vivo evaluation of gene therapy vectors in ex vivo-derived marrow stromal cells for bone regeneration in a rat critical-size calvarial defect model. Hum Gene Ther 14: 1689-1701.

Caplan AI. 1991; Mesenchymal stem cells, $J$ Orthop Res 9: 641-650

Caretti V, Zondervan I, Meijer DH et al. 2011; Monitoring of tumor growth and post-irradiation recurrence in a diffuse intrinsic pontine glioma mouse model. Brain Pathol 21: 441-451.

Chatterjea A, Meijer G, van Blitterswijk C et al. 2010; Clinical application of human mesenchymal stromal cells for bone tissue engineering. Stem Cells Int 2010: 215625.

Colter DC, Class R, DiGirolamo CM et al. 2000; Rapid expansion of recycling stem cells in cultures of plastic-adherent cells from human bone marrow. Proc Natl Acad Sci USA 97: 3213-3218.

Colter DC, Sekiya I, Prockop DJ. 2001; Identification of a subpopulation of rapidly self-renewing and multipotential adult stem cells in colonies of human marrow stromal cells. Proc Natl Acad Sci USA 98: 7841-7845.

Contag CH, Bachmann MH. 2002; Advances in in vivo bioluminescence imaging of gene expression. Annu Rev Biomed Eng 4: 235-260.

De Boer J, van Blitterswijk C, Löwik C. 2006; Bioluminescent imaging: emerging technology for non-invasive imaging of bone tissue engineering. Biomaterials 27: 1851-1858.

Degano IR, Vilalta M, Bago JR et al. 2008; Bioluminescence imaging of calvarial bone repair using bone marrow and adipose tissue-derived mesenchymal stem cells. Biomaterials 29: 427-437.

Digirolamo CM, Stokes D, Colter D et al. 1999; Propagation and senescence of human marrow stromal cells in culture: a simple colony-forming assay identifies samples with the greatest potential to propagate and differentiate. Br J Haematol 107: 275-281.

Dominici M, Paolucci P, Conte P et al. 2009 Heterogeneity of multipotent mesenchymal stromal cells: from stromal cells to stem cells and vice versa. Transplantation 87: S36-42.

Fernandes H, Mentink A, Bank R et al. 2010; Endogenous collagen influences differentiation of human multipotent mesenchymal stromal cells. Tissue Eng Part A 16: 1693-1702.

Friedenstein AJ, Gorskaja JF, Kulagina NN. 1976; Fibroblast precursors in normal and irradiated mouse hematopoietic organs. Exp Hematol 4: 267-274.

Geuze RE, Everts PA, Kruyt MC et al. 2009; Orthotopic location has limited benefit from allogeneic or autologous multipotent stromal cells seeded on ceramic scaffolds. Tissue Eng Part A 15: 3231-3239.

Geuze RE, Prins HJ, Oner FC et al. 2010; Luciferase labeling for multipotent stromal cell tracking in spinal fusion ver sus ectopic bone tissue engineering in mice and rats. Tissue Eng Part $A$ 16: 3343-3351.

Gronthos S, Zannettino AC, Hay SJ et al. 2003; Molecular and cellular characterisation of highly purified stromal stem cells derived from human bone marrow. $J$ Cell Sci 116: 1827-1835.

Hardy J, Edinger M, Bachmann $\mathrm{MH}$ et al. 2001; Bioluminescence imaging of lymphocyte trafficking in vivo. Exp Hemato 29: 1353-1360.

Honigman A, Zeira E, Ohana P et al. 2001; Imaging transgene expression in live animals. Mol Ther 4: 239-249.

Jiang Y, Jahagirdar BN, Reinhardt RL et al. 2002; Pluripotency of mesenchymal stem cells derived from adult marrow. Nature 418: 41-49.

Klijn RJ, Meijer GJ, Bronkhorst EM et al. 2010; A meta-analysis of histomorphometric results and graft healing time of various biomaterials compared to autologous bone used as sinus floor augmentation material in humans. Tissue Eng Part B Rev 16: 493-507.

Kolf CM, Cho E, Tuan RS. 2007; Mesenchymal stromal cells. Biology of adult mesenchymal stem cells: regulation of niche, self-renewal and differentiation. Arthritis Res Ther 9: 204

Kruyt MC, de Bruijn JD, Wilson CE et al. 2003; Viable osteogenic cells are obligatory for tissue-engineered ectopic bone formation in goats. Tissue Eng 9: 327-336.
Kruyt MC, Persson C, Johansson G et al. 2006; Towards injectable cell-based tissueengineered bone: the effect of different calcium phosphate microparticles and preculturing. Tissue Eng 12: 309-317.

Kruyt MC, Dhert WJ, Oner FC et al. 2007; Analysis of ectopic and orthotopic bone formation in cell-based tissue-engineered constructs in goats. Biomaterials $\mathbf{2 8}$ : 1798-1805.

Kuznetsov SA, Krebsbach PH, Satomura K et al. 1997; Single-colony derived strains of human marrow stromal fibroblasts form bone after transplantation in vivo. $J$ Bone Miner Res 12: 1335-1347.

Lee CC, Christensen JE, Yoder MC et al. 2010; Clonal analysis and hierarchy of human bone marrow mesenchymal stem and progenitor cells. Exp Hematol 38: 46-54.

Li S, De Wijn JR, Li J et al. 2003; Macroporous biphasic calcium phosphate scaffold with high permeability/porosity ratio. Tissue Eng 9: 535-548.

Liu J, Barradas A, Fernandes H et al. 2010; In vitro and in vivo bioluminescent imaging of hypoxia in tissue-engineered grafts. Tissue Eng Part C Methods 16: 479-485.

Na IK, Markley JC, Tsai JJ et al. 2010; Concurrent visualization of trafficking, expansion, and activation of $\mathrm{T}$ lymphocytes and $\mathrm{T}$ cell precursors in vivo. Blood 116: e18-25.

Olivo C, Alblas J, Verweij V et al. 2008; In vivo bioluminescence imaging study to monitor ectopic bone formation by luciferase gene marked mesenchymal stem cells. J Orthop Res 26: 901-909.

Paroo Z, Bollinger RA, Braasch DA et al. 2004; Validating bioluminescence imaging as a high-throughput, quantitative modality for assessing tumor burden. Mol Imaging 3: 117-124.

Phinney DG. 2012; Functional heterogeneity of mesenchymal stem cells: implications for cell therapy. $J$ Cell Biochem 13: 2806-2812.

Pittenger MF, Mackay AM, Beck SC et al. 1999; Multilineage potential of adult human mesenchymal stem cells. Science 284: 143-147.

Porada CD, Zanjani ED, Almeida-Porad G. 2006; Adult mesenchymal stem cells: a pluripotent population with multiple applications. Curr Stem Cell Res Ther 1: 365-369.

Postnov AA, Rozemuller H, Verwey V et al. 2009; Correlation of high-resolution X-ray micro-computed tomography with bioluminescence imaging of multiple myeloma 
growth in a xenograft mouse model. Calcif Tissue Int 85: 434-443.

Prins HJ, Rozemuller $\mathrm{H}$, Vonk-Griffioen S et al. 2009; Bone-forming capacity of mesenchymal stromal cells when cultured in the presence of human platelet lysate as substitute for fetal bovine serum. Tissue Eng Part A 15: 3741-3751.

Prockop DJ. 1997; Marrow stromal cells as stem cells for nonhematopoietic tissues. Science 276: 71-74.

Quarto R, Mastrogiacomo M, Cancedda Ret al. 2001; Repair of large bone defects with the use of autologous bone marrow stromal cells. N Engl J Med 344: 385-386.

Rabinovich BA, Ye Y, Etto T et al. 2008; Visualizing fewer than 10 mouse T cells with an enhanced firefly luciferase in immunocompetent mouse models of cancer. Proc Natl Acad Sci USA 105: 14342-14346.

Rozemuller H, van der Spek E, Bogers-Boer LH et al. 2008; A bioluminescence imaging based in vivo model for preclinical testing of novel cellular immunotherapy strategies to improve the graft-versus-myeloma effect. Haematologica 93: 1049-1057.

Russell KC, Phinney DG, Lacey MR et al. 2010; In vitro high-capacity assay to quantify the clonal heterogeneity in trilineage potential of mesenchymal stem cells reveals a complex hierarchy of lineage commitment. Stem Cells 28: 788-798.

Sarugaser R, Hanoun L, Keating A et al. 2009; Human mesenchymal stem cells self-renew and differentiate according to a deterministic hierarchy. PLoS One 4: e6498.

Schimming R, Schmelzeisen R. 2004; Tissueengineered bone for maxillary sinus augmentation. $J$ Oral Maxillofac Surg 62: 724-729.

Schop D, Janssen FW, van Rijn LD et al. 2009; Growth, metabolism, and growth inhibitors of mesenchymal stem cells. Tissue Eng Part A 15: 1877-1886.

Sekiya I, Larson BL, Smith JR et al. 2002; Expansion of human adult stem cells from bone marrow stroma: conditions that maximize the yields of early progenitors and evaluate their quality. Stem Cells $\mathbf{2 0}$ : 530-541.

Siddappa R, Licht R, van Blitterswijk C et al. 2007; Donor variation and loss of multipotency during in vitro expansion of human mesenchymal stem cells for bone tissue engineering. J Orthop Res 25: 1029-1041. Siddappa R, Martens A, Doorn J et al. 2008; cAMP/PKA pathway activation in human mesenchymal stem cells in vitro results in robust bone formation in vivo. Proc Natl Acad Sci USA 105: 7281-7286.

Song IH, Caplan AI, Dennis JE. 2009; In vitro dexamethasone pretreatment enhances bone formation of human mesenchymal stem cells in vivo. J Orthop Res 27: 916-921.

Teixeira S, Fernandes H, Leusink A et al. 2010; In vivo evaluation of highly macroporous ceramic scaffolds for bone tissue engineering. J Biomed Mater Res A 93: 567-575.

Smith JR, Pochampally R, Perry A et al. 2004; Isolation of a highly clonogenic and multipotential subfraction of adult stem cells from bone marrow stroma. Stem Cells 22: 823-831.

Wilson-Hench J. 1987; Definitions in biomaterials. In Progress in Biomedical Engineering, Williams DF (ed.). Elsevier: Amsterdam; 29.

Wu JC, Sundaresan G, Iyer M et al. 2001; Noninvasive optical imaging of firefly luciferase reporter gene expression in skeletal muscles of living mice. Mol Ther 4: 297-306.

Würdinger T, Badr C, Pike L et al. 2008; A secreted luciferase for ex vivo monitoring of in vivo processes. Nat Methods 5: 171-173.

Yuan H, Van Den Doel M, Li S et al. 2002; A comparison of the osteoinductive potential of two calcium phosphate ceramics implanted intramuscularly in goats. $J$ Mater Sci Mater Med 13: 1271-1275.

Yuan H, Fernandes H, Habibovic P et al. 2010; Osteoinductive ceramics as a synthetic alternative to autologous bone grafting. Proc Natl Acad Sci USA 107: 13614-13619.

Zuk PA, Zhu M, Mizuno H et al. 2001; Multilineage cells from human adipose tissue: implications for cell-based therapies. Tissue Eng 7: 211-228. 